\title{
$\alpha$-klotho and anemia in patients with chronic kidney disease patients: A new perspective (Review)
}

\author{
YANG XU ${ }^{1 *}, \mathrm{HAO} \mathrm{PENG}^{2 *}$ and $\mathrm{BEN} \mathrm{KE}{ }^{1}$ \\ ${ }^{1}$ Department of Nephrology, The Second Affiliated Hospital of Nanchang University; \\ ${ }^{2}$ Nanchang University School of Medicine, Nanchang, Jiangxi 330006, P.R. China
}

Received October 7, 2016; Accepted April 11, 2017

DOI: $10.3892 /$ etm.2017.5287

\begin{abstract}
Normocytic normochromic anemia is a common complication of chronic kidney disease (CKD) and is associated with numerous adverse consequences. Certain symptoms previously attributed to CKD are now known to be a consequence of anemia. Anemia contributes to an increased cardiac output, and the development of left ventricular hypertrophy, angina and congestive heart failure, leading to high morbidity and mortality in patients with CKD. The multifunctional $\alpha$-klotho (KL) protein, which is predominantly expressed in the kidneys, is associated with the occurrence of anemia in patients with CKD. The present review presents current evidence on the potential role of $\alpha$-KL in renal anemia. Low expression of $\alpha-K L$ appears to improve anemia in patients with CKD, and has been hypothesized to be a compensatory mechanism to attenuate the effects of anemia in patients with CKD. Further understanding of the role of $\alpha-\mathrm{KL}$ in renal anemia may offer novel insights into the treatment of patients with CKD complicated with anemia.
\end{abstract}

\section{Contents}

1. Introduction

2. Generation and function of $\mathrm{KL}$

3. Association between $\alpha-\mathrm{KL}$ and anemia in CKD

4. Conclusions

Correspondence to: Dr Ben Ke, Department of Nephrology, The Second Affiliated Hospital of Nanchang University, 1 Minde Road, Nanchang, Jiangxi 330006, P.R. China

E-mail: keben-1989125@163.com

*Contributed equally

Key words: klotho, anemia, erythropoietin, iron, vitamin D, chronic kidney disease

\section{Introduction}

Normocytic normochromic anemia is one of the hallmarks of progressive chronic kidney disease (CKD). Normocytic normochromic anemia is defined by a decrease in hemoglobin (Hb) to $<130 \mathrm{~g} / 1$ in men and $<120 \mathrm{~g} / 1$ in women (1). Relatively little is known about the development and progression of anemia in patients with CKD. As kidney function declines in patients with advanced CKD, the incidence of anemia increases (2). The occurrence of anemia in patients with CKD (renal anemia) is primarily due to an absolute or relative decrease in erythropoietin (EPO) production by the failing kidney (1). However, other factors, including iron and vitamin deficiency, in addition to inflammation, contribute to the development of anemia and reduced response to treatment in patients with CKD (2).

Erythropoiesis-stimulating agents (ESAs) and adjuvant iron therapy are the primary methods for treating anemia associated with CKD. ESAs potent and can increase HGB levels significantly. However, recombinant ESAs are expensive, require cold storage and are administered by the parenteral route. In addition, with frequent subcutaneous administrations, ESA therapy is cumbersome for the long-term treatment of dialysis-independent patients with CKD. Furthermore, in patients with CKD undergoing hemodialysis, intravenous administration of ESAs increases the hospital's workload. Recent clinical trials have demonstrated that higher $\mathrm{Hb}$ targets $(\geq 11.3 \mathrm{~g} / \mathrm{dl})$ and/or the application of high doses of ESAs may increase cardiovascular risk (3-5). Therefore, the identification of novel drugs to treat CKD-associated anemia is an important issue.

Klotho $(K L)$ was originally identified as an anti-aging gene, which when overexpressed extended the lifespan of mice (6). The $K L$ gene encodes a single-pass transmembrane protein, and is expressed in the kidney and parathyroid gland (7). Furthermore, the KL protein functions as an obligate subunit of the receptor for fibroblast growth factor 23 (FGF23) (8). FGF23 is a hormone secreted by osteocytes and osteoblasts, which acts on renal tubular cells to promote phosphate excretion into the urine and suppress the synthesis of the active form of vitamin D [1,25-dihydroxyvitamin D3; 1,25(OH)2D3] (9). Growing evidence suggests that $\alpha-\mathrm{KL}$ is a significant marker for CKD $(10,11)$ and a pathogenic factor in the progression of CKD progression $(12,13)$. A recent study has reported that 
decreasing $\alpha-K L$ levels are associated with the occurrence of anemia in patients with CKD (14). The present study reviews the recent advances in understanding of the role served by $\alpha-\mathrm{KL}$ in the development of anemia in patients with CKD, and summarizes novel approaches for the clinical treatment of anemia in CKD.

\section{Generation and function of $\mathrm{KL}$}

The $\alpha$-KL protein is encoded by the $K L$ gene, which was identified in 1997 (7). To date, three types of $\alpha$-KL protein have been identified: Full-length transmembrane, soluble and secreted $\alpha$-KL (15). The full-length $\alpha-\mathrm{KL}$ protein is a transmembrane protein that contains two separate glycosyl hydrolase domains, KL1 and KL2. The truncated $\alpha$-KL protein, also known as soluble $\alpha-\mathrm{KL}$, is released from the cell membrane and may contain KL1 or KL1 and KL2 (16). Soluble $\alpha-\mathrm{KL}$ is generated from the cleavage of the membrane form of KL by $\alpha$ - and $\beta$-secretases ( $\alpha$-cut, KL1 and KL2 domains, $130 \mathrm{kDa} ; \beta$-cut, KL1 domain only, $\sim 65 \mathrm{kDa}$ ) and by insulin stimulation (16). The cleaving process is inhibited by a phosphoinositide 3-kinase (PI3K) inhibitor, which suggests that PI3K serves a role in the cleavage process (17). Secreted $\alpha-\mathrm{KL}(\sim 65 \mathrm{kDa})$, generated by alternative RNA splicing, is the primary form of circulating KL and contains only the KL1 domain, in which the acid/base site is mutated and the nucleophile site is conserved (16). Total circulating $\alpha-\mathrm{KL}$ may include soluble and secreted $\alpha-\mathrm{KL}$. Circulating $\alpha-\mathrm{KL}$ is able to function as a hormone to regulate the functions of cells or tissues that do not express $\alpha$-KL (16). Secreted $\alpha$-KL and the shorter form of soluble $\alpha$-KL contain the KL1 domain and have approximately the same molecular weight ( $65 \mathrm{kDa})(16)$.

$\alpha-\mathrm{KL}$ is a multifunctional protein that regulates essential cellular processes and is predominantly expressed in the kidneys (18). In addition to its anti-aging function, $\alpha-K L$ serves an essential role in the phosphatonin FGF23 signaling pathway and secreted KL functions as an endocrine hormone (19). Previous studies have identified that $\alpha-\mathrm{KL}$ is associated with a range of diseases, including periodontitis (20), cardiovascular disease (21) and kidney disease (18). However, the role of $\alpha-\mathrm{KL}$ in hemopathies, including anemia, remains unclear.

\section{Association between $\alpha-K L$ and anemia in CKD}

Erythropoietin (EPO) and $\alpha-K L$. The release of EPO by the kidneys, a hormone that is important in the regulation of erythropoiesis, is triggered by tissue hypoxia (22). Under hypoxic conditions, EPO stimulates the differentiation of erythroid progenitor cells and normoblasts to increase the amount of red blood cell (RBCs) (22). Hypoxia-inducible factors (HIFs) are heterodimeric proteins that regulate the physiological response to hypoxia by altering the expression of downstream genes, including EPO, in interstitial cells in the renal cortex near the proximal tubule (23).

There may be a negative feedback between EPO and $\alpha-\mathrm{KL}$ such that EPO promotes the expression of $\alpha$-KL and increasing $\alpha$-KL suppresses the production of EPO in CKD $(22,24)$. KL deficiency is a characteristic feature of CKD with anemia (22). $\mathrm{Hu}$ et al (10) revealed that KL expression was reduced during the progression of kidney disease. In addition, the treatment of anemia with EPO has been demonstrated to enhance renal and extrarenal production of $\alpha-\mathrm{KL}$ in patients with CKD $(14,24)$. Furthermore, EPO has been demonstrated to inhibit uremia-induced nuclear factor- $\kappa \mathrm{B}(\mathrm{NF}-\kappa \mathrm{B})$ production in endothelial cells and prevented a decrease in intracellular KL (24). However, a previous study reported that KL directly regulates hematopoietic stem cell differentiation, and erythroid cell generation and maturation (22). KL deficiency in mice resulted in increased erythropoiesis through activation of the HIF signaling pathway, and subsequent upregulation of renal EPO synthesis and secretion (22). Additionally, the expression of HIF- $1 \alpha$ and HIF-2 $\alpha$ was significantly upregulated in $\mathrm{KL}^{-}$ bone tissue, resulting in localized overexpression of EPO (22). The molecular mechanism responsible for the KL-induced inhibition of the HIF signaling pathway and EPO expression may be associated with reduced osteoblast numbers and osteopenia (22). The effects of $\alpha-\mathrm{KL}$ on EPO and the HIF signaling pathway are summarized in Fig. 1.

Kempe et al (25) demonstrated that a lack of KL expression leads to increased cytosolic $\mathrm{Ca}^{2+}$ activity, leading to enhanced scrambling of cell membrane phospholipids and cell shrinkage in erythrocytes. This suggests that KL deficiency accelerates eryptosis, the suicidal death of erythrocytes. Thus, the role of $\mathrm{KL}$ in hemopoiesis remains unclear and further studies into this area are warranted.

Iron metabolism and $\alpha$-KL. Iron-deficiency anemia (IDA) is responsible for $\sim 50 \%$ of all anemia cases (26). It has been reported that 273,000 individuals succumb to IDA each year worldwide (26). 'Absolute' iron deficiency is common in patients with CKD and anemia (27). Different conditions, including inflammation, liver disease and pregnancy, may induce iron-restricted erythropoiesis and aggravate renal anemia (1). The distinction between these conditions is clinically relevant; however, peripheral iron indices are of little help in the differential diagnosis (28).

Iron deficiency may lead to high expression of KL in patients with CKD. A study of 70 patients with stages I-V CKD demonstrated that the FGF23 levels were elevated and KL levels were decreased, and the magnitude of these changes increased as the tumor stage increased (29). In addition, significant correlations were identified between serum KL levels and ferritin levels, and serum KL levels and transferrin saturation percentage, which suggest that KL serves a negative role in iron regulation (29). However, little is known about the underlying molecular mechanisms of these effects. A previous study demonstrated that serum iron overload decreased renal expression of KL at the mRNA and protein levels, and that iron chelation suppressed angiotensin II-induced downregulation of KL (30). These results indicate that the underlying mechanism of the angiotensin II-induced downregulation of $\mathrm{KL}$ is the alteration of iron metabolism in the kidney. Therefore, the renin-angiotensin system may serve a role in the regulation of iron and $\alpha-\mathrm{KL}$.

HIFs affect the majority of aspects of iron metabolism (23). HIF-2 enhances iron absorption by small bowel enterocytes and augments iron export from duodenal cells (23). Additionally, HIFs serve a role in the utilization of iron from senescent RBCs via reticuloendothelial system macrophages (31). In this manner HIFs increases iron stores through absorption 


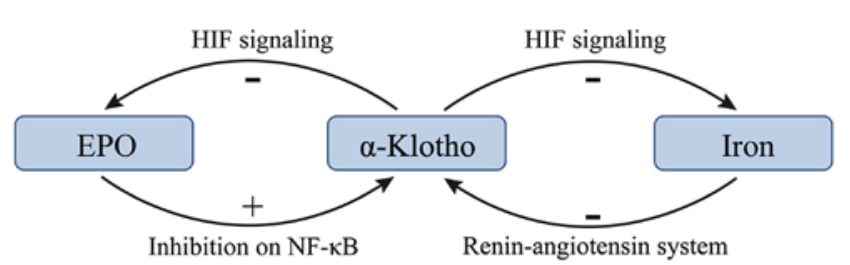

Figure 1. Low expression of $\alpha$-Klotho in patients with chronic kidney disease complicated by anemia could increase serum EPO and iron levels. HIF, hypoxia-inducible factor; EPO, erythropoietin; $N F-\kappa B$, nuclear factor- $\kappa \mathrm{B}$.

from the duodenum and the recycling of senescent RBCs (31). The increased efflux of iron to the circulation is achieved via HIF-mediated increased expression of ferroportin in duodenal enterocytes and macrophages (31). KL deficiency in mice results in the activation of the HIF signaling pathway (22). The effects the HIF signaling pathway on iron supplies are summarized in Fig. 1.

Vitamin $D$ and $\alpha$-KL. Accumulating evidence suggests that vitamin $\mathrm{D}$ deficiency increased the progression of CKD (32-34). Vitamin D is important in anemia, with low vitamin $\mathrm{D}$ levels being associated with an increased risk of anemia $(35,36)$. Thus, vitamin D deficiency may be a factor in the development of anemia in patients with CKD.

Vitamin D and KL exert negative feedback towards one another in patients with renal anemia. A previous study suggested that the vitamin D/parathyroid hormone (PTH) signaling pathway regulates the KL/FGF23 signaling pathway, and vice versa (37). 1,25-dihydroxyvitamin D $[1,25(\mathrm{OH}) \mathrm{D} 2]$, the metabolically active form of vitamin $\mathrm{D}$, was demonstrated to upregulate KL expression (37). PTH may indirectly upregulate KL via upregulating 1,25(OH)D2 (38). In addition, several recent studies have demonstrated that vitamin D stimulates the expression of FGF23 and KL, and that vitamin $\mathrm{D}$ formation is limited by a negative feedback regulation (39-41). This negative feedback is lost in $\mathrm{kl}^{-} / \mathrm{kl}^{-}$ mice and in these mice the formation of $1,25(\mathrm{OH}) 2 \mathrm{D} 3$ is a function of dietary vitamin $\mathrm{D}$ even at excessive $1,25(\mathrm{OH}) 2 \mathrm{D} 3$ concentrations (42). The mechanism by which KL inhibits the production of $1,25(\mathrm{OH}) 2 \mathrm{D} 3$ may be via inhibiting 25-hydroxyvitamin D $1 \alpha$-hydroxylase (39). A summary of the current knowledge of the association between vitamin $\mathrm{D}$ and $\alpha-\mathrm{KL}$ is presented in Fig. 2 .

Inflammation and $\alpha-K L$. Inflammation is an essential component to the body's defense system; however, excessive inflammation is considered to be the cause of anemia in patients with CKD (43). Inflammatory cells release large amounts of chemokines and vasoactive factors, including monocyte chemotactic protein-1 (MCP-1) and NF- $\kappa \mathrm{B}$, which induce the production of profibrotic cytokines following kidney injury (44). At the site of injury, proinflammatory factors, including interleukin (IL)-12, MCP-1 and $\mathrm{NF}-\kappa \mathrm{B}$, stimulate the generation of myofibroblasts and the deposition of extracellular matrix, eventually leading to renal dysfunction and potentially to the indirect development of anemia (45). Notably, anemia is a common complication in patients with infections, autoimmune disorders,

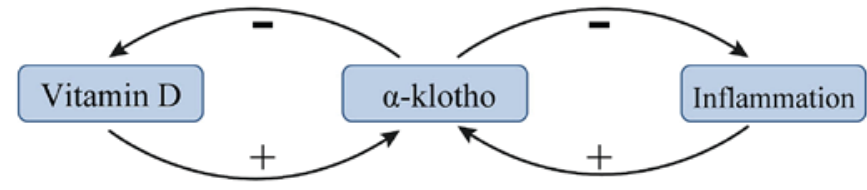

Figure 2. Low expression of $\alpha$-Klotho in patients with chronic kidney disease complicated by anemia could increase serum vitamin D levels and inhibit inflammation.

malignancies, CKD and other inflammation-associated disorders (46). Inflammatory cytokines impair erythropoiesis by inhibiting the production and function of EPO, and inhibiting erythroid progenitor cell proliferation and differentiation. Notably, inflammation induces the expression of iron regulatory hormone hepcidin and suppresses the iron exporter ferroportin, restricting the supply of iron for erythropoiesis (46).

$\mathrm{KL}$ is known to be an inhibitor of several inflammatory cytokines (47). The transcription factor $\mathrm{NF}-\kappa \mathrm{B}$ is an important stimulator of inflammation in CKD (48). A recent study reported that intracellular KL diminished the DNA binding ability of $\mathrm{NF}-\kappa \mathrm{B}$ and stabilized the $\mathrm{NF}-\kappa \mathrm{B} / \mathrm{NF}-\kappa \mathrm{B}$ inhibitor $\alpha$ complex, thus preventing uremia-induced $\mathrm{NF}-\kappa \mathrm{B}$ expression (24). KL serves as an anti-inflammatory modulator through negatively regulating the production of $\mathrm{NF}-\kappa \mathrm{B}$-associated inflammatory proteins (47). A potential mechanism for this effect is that KL inhibits the Ser ${ }^{536}$ phosphorylation of the NF- $\mathrm{B}$ p65 subunit and its subsequent recruitment to the promoter sites of multiple cytokines (49). Additionally, KL may attenuate the glucose-stimulated activation of the $\mathrm{NF}-\kappa \mathrm{B}$ by downregulating the expression of toll-like receptor 4 (50), which is associated with $\mathrm{CKD}$ (51). Conversely, $\mathrm{NF}-\kappa \mathrm{B}$ regulates the activity of exogenous and intracellular KL in endothelial cells (52). NF- $\kappa \mathrm{B}$ also suppresses the activity of KL, potentially by promoting the production of reactive oxygen species (52). Finally, NF- $\kappa \mathrm{B}$ also inhibits the proinflammatory effect of IL-12 (20). These results demonstrate the anti-inflammatory effects of KL (Fig. 2).

\section{Conclusions}

Although several studies have reported that there is reduction of $\alpha-\mathrm{KL}$ in patients with CKD with anemia, the mechanisms are complicated. Based on previous studies, it appears that low levels of EPO in patients with CKD with anemia downregulates the expression of $\alpha$-KL, which results in high serum levels of iron and vitamin $\mathrm{D}$, mitigating anemia. This suggests that low expression of $\alpha-\mathrm{KL}$ may be a compensatory mechanism to attenuate the effects of anemia. Meanwhile, the expression of $\alpha-\mathrm{KL}$ declines when serum levels of iron increase, and the expression of $\alpha$-KL increases with vitamin D. Overall, further understanding of the role of $\alpha-\mathrm{KL}$ in renal anemia is needed, which may offer novel insights into the treatment of patients with CKD complicated with anemia.

\section{Acknowledgements}

The present study was supported by the National Natural Science Foundation of China (grant no. 81460142). 


\section{References}

1. Zadrazil $\mathrm{J}$ and Horak P: Pathophysiology of anemia in chronic kidney diseases: A review. Biomed Pap Med Fac Univ Palacky Olomouc Czech Repub 159: 197-202, 2015.

2. Collister D, Ferguson T, Komenda P and Tangri N: The patterns, risk factors and prediction of progression in chronic kidney disease: A narrative review. Semin Nephrol 36: 273-282, 2016.

3. Singh AK, Szczech L, Tang KL, Barnhart H, Sapp S, Wolfson M and Reddan D; CHOIR Investigators: Correction of anemia with epoetin alfa in chronic kidney disease. N Engl J Med 355 2085-2098, 2006.

4. Drüeke TB, Locatelli F, Clyne N, Eckardt KU, Macdougall IC, Tsakiris D, Burger HU and Scherhag A; CREATE Investigators: Normalization of hemoglobin level in patients with chronic kidney disease and anemia. N Engl J Med 355: 2071-2084, 2006.

5. Pfeffer MA, Burdmann EA, Chen CY, Cooper ME, de Zeeuw D, Eckardt KU, Feyzi JM, Ivanovich P, Kewalramani R, Levey AS, et al: A trial of darbepoetin alfa in type 2 diabetes and chronic kidney disease. N Engl J Med 361: 2019-2032, 2009

6. Akasaka-Manya K, Manya H and Endo T: Function and change with aging of alpha-klotho in the kidney. Vitam and horm 101: 239-256, 2016.

7. Kuro-o M, Matsumura Y, Aizawa H, Kawaguchi H, Suga T, Utsugi T, Ohyama Y, Kurabayashi M, Kaname T, Kume E, et al: Mutation of the mouse klotho gene leads to a syndrome resembling ageing. Nature 390: 45-51, 1997.

8. Kurosu $\mathrm{H}$ and Kuro OM: The Klotho gene family as a regulator of endocrine fibroblast growth factors. Mol Cell Endocrinol 299: $72-78,2009$.

9. Ide N, Olauson H, Sato T, Densmore MJ, Wang H, Hanai JI, Larsson TE and Lanske B: In vivo evidence for a limited role of proximal tubular klotho in renal phosphate handling. Kidney Int 99: 348-362: 2016.

10. Hu MC, Shi M, Zhang J, Addo T, Cho HJ, Barker SL, Ravikumar P, Gillings N, Bian A, Sidhu SS, et al: Renal production, uptake and handling of circulating $\alpha$ Klotho. J Am Soc Nephrol 27: 79-90, 2016.

11. Zhou L, Mo H, Miao J, Zhou D, Tan RJ, Hou FF and Liu Y: Klotho ameliorates kidney injury and fibrosis and normalizes blood pressure by targeting the renin-angiotensin system. Am J Pathol 185: 3211-3223, 2015.

12. Kadoya H, Satoh M, Haruna Y, Sasaki T and Kashihara N: Klotho attenuates renal hypertrophy and glomerular injury in Ins2Akita diabetic mice. Clin Exp Nephrol 20: 671-678, 2016.

13. Xie J, Yoon J, An SW, Kuro-o M and Huang CL: Soluble klotho protects against uremic cardiomyopathy independently of fibroblast growth factor 23 and phosphate. J Am Soc Nephrol 26 : 1150-1160, 2015.

14. Milovanov YS, Mukhin NA, Kozlovskaya LV, Milovanova SY and Markina MM: Impact of anemia correction on the production of the circulating morphogenetic protein alpha-Klotho in patients with stages 3B-4 chronic kidney disease: A new direction of cardionephroprotection. Ter Arkh 88: 21-25, 2016 (In Russian; Abstract available in Russian from the publisher).

15. Wang Y and Sun Z: Current understanding of klotho. Ageing Res Rev 8: 43-51, 2009.

16. $\mathrm{Xu} \mathrm{Y}$ and Sun Z: Molecular basis of Klotho: from gene to function in aging. Endocr Rev 36: 174-193, 2015.

17. Chen CD, Podvin S, Gillespie E, Leeman SE and Abraham CR: Insulin stimulates the cleavage and release of the extracellular domain of Klotho by ADAM10 and ADAM17. Proc Natl Acad Sci USA 104: 19796-19801, 2007.

18. Olauson H, Lindberg K, Amin R, Jia T, Wernerson A, Andersson G and Larsson TE: Targeted deletion of Klotho in kidney distal tubule disrupts mineral metabolism. J Am Soc Nephrol 23: 1641-1651, 2012.

19. Martin A, David V and Quarles LD: Regulation and function of the FGF23/klotho endocrine pathways. Physiol Rev 92: 131-155, 2012.

20. Liu Y and Zhang Q: Periodontitis aggravated pancreatic beta-cell dysfunction in diabetic mice through interleukin-12 regulation on Klotho. J Diabetes Investig 7: 303-311, 2016.

21. Chen J, Lin Y and Sun Z: Deficiency in the anti-aging gene Klotho promotes aortic valve fibrosis through AMPK $\alpha$-mediated activation of RUNX2. Aging cell 15: 853-860: 2016.

22. Vadakke Madathil S, Coe LM, Casu C and Sitara D: Klotho deficiency disrupts hematopoietic stem cell development and erythropoiesis. Am J Pathol 184: 827-841, 2014.
23. Solak Y, Cetiner M, Siriopol D, Tarim K, Afsar B, Covic A and Kanbay M: Novel masters of erythropoiesis: hypoxia inducible factors and recent advances in anemia of renal disease. Blood purif 42: 160-167, 2016

24. Buendia P, Carracedo J, Soriano S, Madueño JA, Ortiz A, Martín-Malo A, Aljama P and Ramírez R: Klotho prevents $\mathrm{NF} \kappa \mathrm{B}$ translocation and protects endothelial cell from senescence induced by uremia. J Gerontol A Biol Sci Med Sci 70 1198-1209, 2015.

25. Kempe DS, Ackermann TF, Fischer SS, Koka S, Boini KM, Mahmud H, Föller M, Rosenblatt KP, Kuro-O M and Lang F: Accelerated suicidal erythrocyte death in Klotho-deficient mice. Pflugers Arch 458: 503-512, 2009.

26. Pasricha SR, Drakesmith H, Black J, Hipgrave D and Biggs BA: Control of iron deficiency anemia in low- and middle-income countries. Blood 121: 2607-2617, 2013.

27. Stancu S, Stanciu A, Zugravu A, Bârsan L, Dumitru D, Lipan M and Mircescu G: Bone marrow iron, iron indices and the response to intravenous iron in patients with non-dialysis-dependent CKD. Am J Kidney Dis 55: 639-647, 2010.

28. Barsan L, Stanciu A, Stancu S, Căpuşă C, Brătescu L, Mandache E, Radu E and Mircescu G: Bone marrow iron distribution, hepcidin and ferroportin expression in renal anemia. Hematology 20: 543-552, 2015.

29. Milovanova L, Milovanov Iu S, Kozlovskaia LV and Mukhin NA Significance of the morphogenetic proteins FGF-23 and Klotho as predictors of prognosis of chronic kidney disease. Ter Arkh 86: 36-44, 2014 (In Russian).

30. Saito K, Ishizaka N, Mitani H, Ohno M and Nagai R: Iron chelation and a free radical scavenger suppress angiotensin II-induced downregulation of klotho, an anti-aging gene, in rat. FEBS Lett 551: 58-62, 2003.

31. Taylor M, Qu A, Anderson ER, Matsubara T, Martin A, Gonzalez FJ and Shah YM: Hypoxia-inducible factor- $2 \alpha$ mediates the adaptive increase of intestinal ferroportin during iron deficiency in mice. Gastroenterology 140: 2044-2055, 2011.

32. Goncalves JG, de Braganca AC, Canale D, Shimizu MH, Sanches TR, Moysés RM, Andrade L, Seguro AC and Volpini RA: Vitamin D deficiency aggravates chronic kidney disease progression after ischemic acute kidney injury. PLoS One 9: e107228, 2014.

33. Goldsmith DJ: Pro: Should we correct vitamin D deficiency/insufficiency in chronic kidney disease patients with inactive forms of vitamin D or just treat them with active vitamin D forms? Nephrol Dial Transplant 31: 698-705, 2016.

34. Agarwal R and Georgianos PI: Con: Nutritional vitamin D replacement in chronic kidney disease and end-stage renal disease. Nephrol Dial Transplant 31: 706-713, 2016.

35. Monlezun DJ, Camargo CA Jr, Mullen JT and Quraishi SA: Vitamin d status and the risk of anemia in community-dwelling adults: Results from the national health and nutrition examination survey 2001-2006. Medicine (Baltimore) 94: e1799, 2015.

36. Suh YJ, Lee JE, Lee DH, Yi HG, Lee MH, Kim CS, Nah JW and Kim SK: Prevalence and relationships of iron deficiency anemia with blood cadmium and vitamin D levels in Korean women. J Korean Med Sci 31: 25-32, 2016.

37. Forster RE, Jurutka PW, Hsieh JC, Haussler CA, Lowmiller CL, Kaneko I, Haussler MR and Kerr Whitfield G: Vitamin D receptor controls expression of the anti-aging klotho gene in mouse and human renal cells. Biochem Biophys Res Commun 414: 557-562, 2011.

38. Lips P: Vitamin D physiology. Prog Biophys Mol Biol 92: 4-8, 2006

39. Kuro-o M: Klotho, phosphate and FGF-23 in ageing and disturbed mineral metabolism. Nat Rev Nephrol 9: 650-660, 2013.

40. Alesutan I, Feger M, Pakladok T, Mia S, Ahmed MS, Voelkl J, Lang F: 25-Hydroxyvitamin D3 1- $\alpha$-hydroxylase-dependent stimulation of renal klotho expression by spironolactone. Kidney Blood Press Res 37: 475-487, 2013.

41. Takenaka T, Inoue T, Ohno Y, Miyazaki T, Nishiyama A, Ishii N and Suzuki H: Calcitriol supplementation improves endothelium-dependent vasodilation in rat hypertensive renal injury. Kidney Blood Press Res 39: 17-27, 2014.

42. Leibrock CB, Voelkl J, Kuro-O M, Lang F and Lang UE: $1,25(\mathrm{OH}) 2 \mathrm{D} 3$ dependent overt hyperactivity phenotype in klotho-hypomorphic mice. Sci Rep 6: 24879, 2016.

43. Ichii O, Nakamura T, Irie T, Kouguchi H, Nakamura D, Nakamura S, Sato S, Yokoyama K, Horino T, Sunden Y, et al: Female cotton rats (Sigmodon hispidus) develop chronic anemia with renal inflammation and cystic changes. Histochem Cell Biol 146: 351-362, 2016 
44. Chung ACK and Lan HY: Chemokines in renal injury. J Am Soc Nephrol 22: 802-809, 2011.

45. Mack M and Yanagita M: Origin of myofibroblasts and cellular events triggering fibrosis. Kidney Int 87: 297-307, 2015.

46. Wang CY and Babitt JL: Hepcidin regulation in the anemia of inflammation. Curr Opin Hematol 23: 189-197, 2016.

47. Kurosu H, Yamamoto M, Clark JD, Pastor JV, Nandi A, Gurnani P, McGuinness OP, Chikuda H, Yamaguchi M, Kawaguchi H, et al: Suppression of aging in mice by the hormone Klotho. Science 309: 1829-1833, 2005.

48. Wada $\mathrm{J}$ and Makino $\mathrm{H}$ : Inflammation and the pathogenesis of diabetic nephropathy. Clin Sci (Lond) 124: 139-152, 2013.

49. Zhao Y, Banerjee S, Dey N, LeJeune WS, Sarkar PS, Brobey R, Rosenblatt KP, Tilton RG and Choudhary S: Klotho depletion contributes to increased inflammation in kidney of the $\mathrm{db} / \mathrm{db}$ mouse model of diabetes via RelA (serine)536 phosphorylation. Diabetes 60: 1907-1916, 2011.
50. Wu C, Lv C, Chen F, Ma X, Shao Y and Wang Q: The function of miR-199a-5p/Klotho regulating TLR4/NF-kappaB p65/NGAL pathways in rat mesangial cells cultured with high glucose and the mechanism. Mol Cell Endocrinol 417: 84-93, 2015.

51. Shao Y, Sha M, Chen L, Li D, Lu J and Xia S: HMGB1/TLR4 signaling induces an inflammatory response following high-pressure renal pelvic perfusion in a porcine model. Am J Physiol Renal Physiol 311: F915-F925, 2016.

52. Yang K, Nie L, Huang Y, Zhang J, Xiao T, Guan X and Zhao J: Amelioration of uremic toxin indoxyl sulfate-induced endothelial cell dysfunction by Klotho protein. Toxicol Lett 215: 77-83, 2012. 